\title{
The Ethics of Regulation
}

\author{
David Antoni \& Freddy Leal
}

\section{Introduction}

Regulations are often imposed in order to correct any failures in the market, whether the failure is a result of the functioning of a market or the behaviour of a government. However, every regulatory intervention brings up a question: How ethical is the regulation? Even if a regulatory intervention could achieve more efficiency or more equity, it may not mean that it is ethical. The concept of ethics is necessarily subjective, it is based on the morals and standards of a society. Yet even though a society may be concerned about ethics, the issues of equity and altruism matter as does the way in which firms produce and seek to rationally and efficiently maximize profit.

Defining ethics is a difficult issue, and defining ethical regulation is even more difficult. Any form of regulation is a tool for intervention used to balance the trade-off between efficiency and equity to create harmony between a market or economy and the society it functions within. In an ideal world, any government intervention implemented would be for the greater benefit of all. However, this does not always happen in the vicissitudes of the real world when governments regulate and intervene in markets, which are, in turn, based on the principle of rational self-interest and efficiency.

In this paper we discuss the role of society in market regulation. The discussion will focus on the importance of society on ethics and therefore on what constitutes ethical regulations. In fact we argue that equity, efficiency or even failures are not the main factors to consider when regulating. It is society that defines ethics and how society understands ethics influences the regulatory environment. 


\section{Equity versus Efficiency}

When looking at market regulation in general, it is necessary to understand the concept of efficiency and equity. There has always been a debate between the relative balance between seeking efficiency and equity, and yet neoclassical economics does not present us with any unique consensus about it. The concept of efficiency is based on the idea that society would produce more with the same scarce resources. Equity is related to the fair distribution of resources among society, and a minimization of discriminatory outcomes. Most economists agree that equity and efficiency must be traded off against each other, the higher the equity the less efficiency is achieved (Blank, 2004).

The problem has been how to achieve the most ethical trade-off between efficiency and equity in the market. Let us consider taxes on inelastic goods as an example. Is it ethical to increase taxes on such goods? When a government intervenes in the market and charges higher taxes, is it doing the best for society? Or is it only trying to maximize tax revenues by creating the least cost on efficiency?

When taxing an inelastic good, the resulting dead weight loss created is minimized and the tax revenue generated is large (see Figure 1). The result is more efficient than it would be taxing an elastic good instead. However, depending on the product that is characterized by inelastic demand, it may not necessarily be "fair" in this trade-off of efficiency for equity After all, cigarettes and petrol both have relatively inelastic demand.

Figures 1 and 2 illustrate the tax effect on an inelastic and an elastic product. A high tax on inelastic products can be seen as exploitation, because demand for the good will not change by as much as price increases. Exploitation of consumers by the government cannot possibly be ethical, so we argue that taxing based on the demand elasticity of a good is bound to be a highly sensitive ethical issue. 
FIGURE 1: INELASTIC PRODUCT

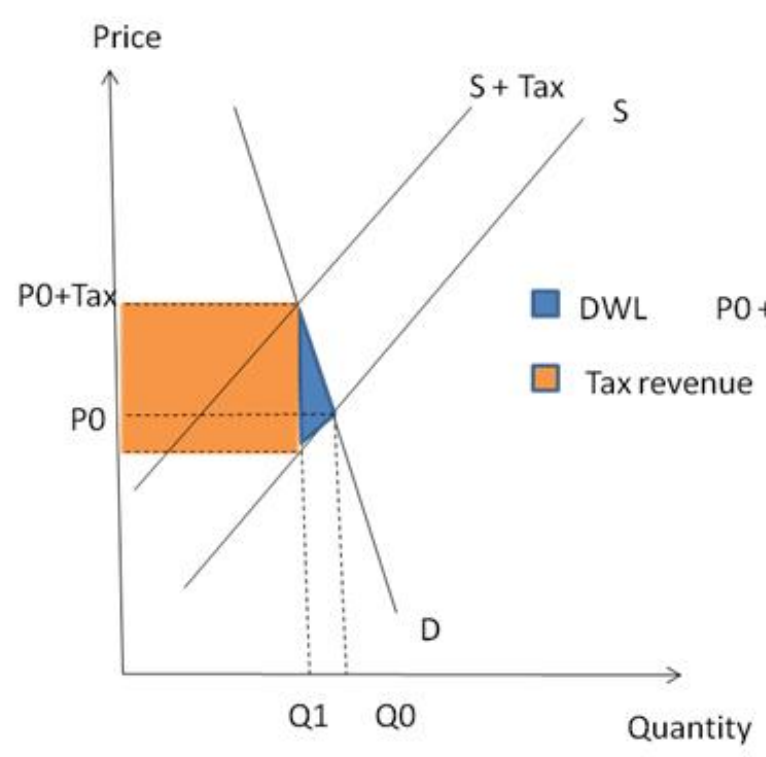

FIGURE2: ELASTIC PRODUCT

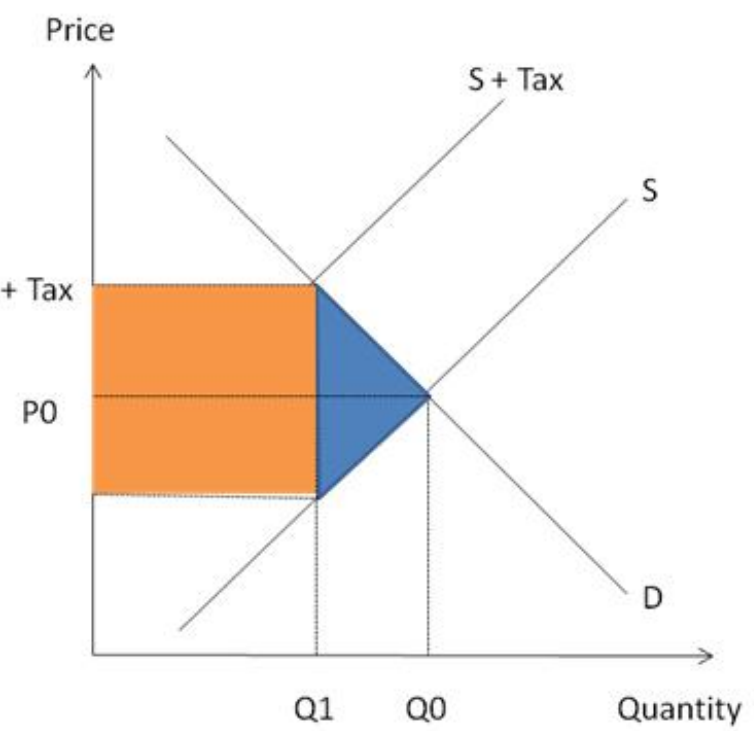

On the other hand regulation could be considered on equity issues prior to efficiency concerns. For example, if person A is working 12 hours a day and person B only 4, and both produce the same average hourly product yet earn the same, then person A is clearly more efficient and should earn more. In this particular case, an equal wage for A and B trades off efficiency for equity and the result is a very equitable society but a very inefficient labour market. 
Both extremes are highly unlikely to occur in the real world, since these scenarios will not produce a wealthy economy and cause choices among consumers and suppliers to distort over time. The issue arising from this is whether or how much a market should be regulated and by what means.

Regulators often give preference to some industries over others, and in some cases prefer some firms or consumers over others. For example, in some markets local participants are given preferences over foreign companies. The wine industry in Australia illustrates this very clearly. According to the Distilled Spirits Industry Council of Australia (2006), the government protects domestic wineries by imposing tariffs on foreign companies, making it hard and expensive for them to enter the market. This sort of intervention which is commonplace around the world suggests the ethic that domestic suppliers are somehow more deserving than international manufacturers.

\section{Market Failure versus Government Failure}

Failures can occur in a free market as well as in a regulated market. Usually market failures occur in free markets, where resources are not allocated efficiently. On the other hand, government failure occurs when governments intervene in the market and the outcome is less efficient than it would have been in the absence of any intervention. Ironically, a government failure could also occur if the government fails to correct an existing market failure.

Both scenarios of failures will create externalities, which are costs imposed on society by market participant that fail to internalize the costs they impose that are external to the market. The aim of regulation is to eliminate the negative externalities or more realistically reduce them to a minimum.

When creating positive externalities, usually negative externalities are sometimes a side effect. For example, if the government decides to prohibit the advertising of alcohol in sports, then a positive externality would be the reduction of people's exposure towards 
alcohol. As a negative side effect (externality) of this could be that the sports economy is missing out on top dollar sponsorships (Lewis and Peckham, 2009).

In terms of ethics, it is debatable whether alcohol or tobacco sponsorship is ethical to begin with. Different countries around the world deal with both issues very differently. Any given government would need to decide whether this would create more costs than benefits to society and the economy. If the government intervenes, it needs to consider what the outcome might be and what externalities it might create.

\section{Tragedy of the Commons versus Tragedy of the Anti-Commons}

When market or government failure occurs, externalities are created. As a result of externalities we could have costs or benefits, however it is still unclear how to measure these accurately. Even in these calculations it is usually necessary to involve ethical standards, and since these are not unique among citizens, it is hard to measure externalities. The regulation of externalities can be usefully illustrated by using the concept of the tragedy of the commons versus the anti-commons.

For instance, in the example of banning sponsorship in sports by an alcoholic beverage producer, a negative externality is that the sports market will lose a sizeable amount of sponsorship revenue. Another externality could be an increase in ticket prices as the sport struggles to compensate the advertising revenue losses. From the perspective of efficiency, alcohol and sports are often closely related, so advertising in this manner is logical.

A market that is unregulated, may deplete its resources very. Even when this might be efficient it can be damaging to the economy when the resource is scarce. This is the message of the tragedy of the commons. However, where a market is highly regulated, market participants might find it hard or costly to operate, and they might be dissuaded from entering the market altogether. In this case, the market could eventually even disappear, a situation that corresponds to the tragedy of the anti-commons. The opportunity is there but it is blocked by excessive regulation. 
Both extremes seem to be unethical. Neither one creates fair value to the citizens or society of a country. This however depends on the standards of ethics in a society, which vary considerably from country to country.

\section{The Role of Society in the Idea of Ethical Market Regulation}

We would argue that the role of society is significant in assessing the ethics of regulation. Society is the foundation of every nation, and what people see as ethical is defined in the culture of each society. For example, in the Middle East it is not only against the law to drink alcohol, but is also seen as unethical by society. The law was most likely put in place because of a society with a given set of standards, including religious views and traditions. The fact is that politicians, market participants and bureaucrats alike are all members of a society that determines the ethical standards for regulation.

The history of a society within a country and how it evolves is arguably the starting point of how each country defines its ethics for market regulation. A court ruling over illegal substances is different in Europe compared to South East Asia. Parents and educational institutions are other factors that suggest how a society learns to see and define ethics. There are many different layers in one society, and each has a different opinion to what is ethical and what is not.

Society shows the market and the government what is needed and accepted, but the influence varies among different cultures. If a firm goes against the ethical code of a society, the resulting performance of the market it operates in could change drastically. For example cigarette advertising in Formula 1 caused uproar some parts of society, and was banned almost immediately when the discussion gained public interest. Society saw it as unethical to advertise addictive products that were damaging to public health.

Figure 3 indicates that society influences how a government treats certain issue. On the contrary, the government also influences society by imposing law and rules. The same occurs with the relationship between the market and the government, the government imposes rules and the market operates within them and yet gives direction to the evolution 
of those rules. Individuals can have an impact on the market, however their direct impact on society is likely to be more muted. From this simple diagram we could argue that it is very difficult for a government to intervene in the market in a manner that is seen as ethical and yet equally acceptable in different contexts. The market and society have an influence on politics, which makes it harder to get the right balance consistently.

FIGURE 3. RELATIONSHIP BETWEEN PARTIES IN THE MARKET.

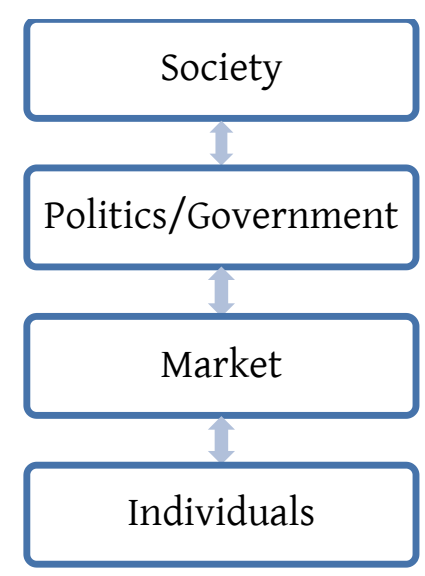

\section{Concluding remarks}

It often appears that society has not much of a direct say in today's modern, rational and market-driven world, but as we have argued in this paper, this is an illusion. Society clearly does play a role in the regulation of markets, by simply defining ethics. Furthermore, it is important to realize that politicians are part of society. When intervening in a market, societies have an impact on the behaviour of politicians. To what extent a regulation favours the balance between equity and efficiency first depends on the ethics of the society in the country, which does vary across countries. We believe that the ethical factor 
involved in regulation should be understood well to understand market regulation better in a rapidly globalizing world.

\section{References}

- Blank, R 2002, Can equity and efficiency complement each other?, National Bureau of Economic Research Inc., Retrieved 05 September 2010 <papers.nber.org/papers/W8820.pdf>.

- DSICA - see Distilled Spirits Industry Council of Australia Distilled Spirits Industry Council of Australia, 2006, Alcohol Tax of Australia 2006, retrieved August 15 2010, <www.dsica.com.au/pdfs/DSICA06-A01.pdf>.

- Lewis, S \& Peckham, B 2009, Call to ban alcohol sponsorship of sport, News.com.au, retrieved 29 August 2010, <www.news.com.au/call-to-ban-alcohol-sponsorship-ofsport/story-0-1225751178639>.

- World Nuclear Organisation, 2010, Australia's Uranium, retrieved 25 September 2010, $<$ www.world-nuclear.org/info/inf48.html>. 